\title{
Effects of endoscopic thoracic sympathectomy for primary hyperhidrosis on cardiac autonomic nervous activity
}

\author{
Jorge Cruz, MD, PhD, ${ }^{\mathrm{a}, \mathrm{c}}$ João Sousa, $\mathrm{MD},{ }^{\mathrm{b}, \mathrm{c}}$ Antonio G. Oliveira, $\mathrm{MD}, \mathrm{PhD},{ }^{\mathrm{d}}$ and Luis Silva-Carvalho, $\mathrm{MD}, \mathrm{PhD}{ }^{\mathrm{e}, \mathrm{f}}$
}

\begin{abstract}
Objective: Endoscopic thoracic sympathectomy is performed to treat primary hyperhidrosis. The second and third sympathetic thoracic ganglia excised also innervate the heart. Some studies have shown decreased heart rate but have not been conclusive regarding other cardiac effects of sympathectomy. We studied the cardiac autonomic effects of endoscopic thoracic sympathectomy in a group of patients with primary hyperhidrosis. Heart rate variability is a simple, noninvasive electrocardiographic marker reflecting the activity and balance of the sympathetic and vagal components of the autonomous nervous system.
\end{abstract}

Methods: We performed a prospective study in 38 patients with primary hyperhidrosis with 24-hour Holter recordings obtained before endoscopic thoracic sympathectomy and 6 months later.

Results: We found statistically significant differences $(P<.05)$ in both time and frequency domains. Parameters that evaluate global cardiac autonomic activity (total power, SD of normal R-R intervals, SD of average normal R$\mathrm{R}$ intervals) and vagal activity (rhythm corresponding to percentage of normal $\mathrm{R}-\mathrm{R}$ intervals with cycle greater than $50 \mathrm{~ms}$ relative to previous interval, square root of mean squared differences of successive normal R-R intervals, high-frequency power, high-frequency power in normalized units) were statistically significantly increased after sympathectomy. Low-frequency power in normalized units, reflecting sympathetic activity, was statistically significantly decreased after sympathectomy. Low-/high-frequency power ratio also showed a significant decrease, indicating relative decrease in sympathetic activity and increase in vagal activity.

Conclusion: These results provide, for the first time to our knowledge, clear evidence of increased vagal and global cardiac autonomic activity and decreased sympathetic activity after endoscopic thoracic sympathectomy.

Endoscopic thoracic sympathectomy (ETS) is performed for the treatment of primary hyperhidrosis. ${ }^{1}$ This minimally invasive procedure of thoracic sympathetic resection consists of the bilateral ablation of the second and third thoracic sympathetic ganglia, affecting the sympathetic nervous outflow to the arms and elsewhere. The results of this operation include a high degree of patient satisfaction with the procedure. $^{1-6}$

The second and third sympathetic thoracic ganglia excised in ETS also innervate the heart. A few studies about this subject have shown a decrease in heart rate but have not been conclusive regarding other cardiac effects of ETS. In this investigation, we studied the cardiac autonomous effects of ETS in a sample of patients with primary hyperhidrosis. Heart rate variability (HRV) is a simple and noninvasive electrocardiographic marker reflecting the activity and balance of the sympathetic and vagal components of the autonomous nervous system on the cardiac sinus

From the Service of Cardiothoracic Surgery ${ }^{\mathrm{a}}$ and Cardiology, ${ }^{\mathrm{b}}$ Hospital de Santa Maria; Instituto Cardiovascular de Lisboa ${ }^{c}$; the Department of Biostatistics, Faculty of Medical Sciences, Universidade Nova de Lisboa ${ }^{\mathrm{d}}$; Instituto de Fisiologia, Faculdade de Medicina de Lisboa ${ }^{\mathrm{e}}$; and Instituto de Medicina Molecular, ${ }^{\mathrm{f}}$ Lisbon, Portugal.

Received for publication Feb 19, 2008; revisions received June 7, 2008; accepted for publication July 6, 2008.

Address for reprints: Jorge Cruz, MD, PhD, Avenida Guerra Junqueiro No. 11-4 Esquerdo 1000-166 Lisboa, Portugal (E-mail: costacruzjorge@gmail.com).

J Thorac Cardiovasc Surg 2009;137:664-9

0022-5223/\$36.00

Copyright (c) 2009 by The American Association for Thoracic Surgery doi:10.1016/j.jtcvs.2008.07.021 node. ${ }^{7-11}$ We therefore decided to perform a prospective analysis of 24-hour Holter recordings in patients with primary hyperhidrosis before and 6 months after ETS.

\section{MATERIALS AND METHODS}

Consecutive patients who were referred to our department for bilateral thoracic sympathectomy for primary hyperhidrosis were included in this prospective study. None of the patients were receiving medication at the time of the study.

Bilateral video-assisted ETS was performed with general anesthesia. All operations were performed by the same surgeon (J.C.), who had experience with more than 400 operations at the time of study initiation. The lung was excluded with a double-lumen tube. We used two incisions on the fourth and fifth intercostal spaces, and in all cases the second and third sympathetic ganglia were destroyed by electrocautery. One chest drain was left in place for about 8 hours after the operation. Patients were discharged from the hospital the day after the operation. The study was approved by the Lisbon Medical School ethics committee and was performed according the Declaration of Helsinki. All patients provided written, informed consent.

Twenty-four-hour Holter recordings were performed 2 weeks before and 6 months after ETS. A 3-channel Spacelab Burdick with the Holter Vision Premier analysis system (Cardiac Science Corporation, Seattle, Wash) was used. The recordings were started systematically at 4:00 PM and were disconnected 24 hours later. Subjects were asked to maintain routine daily activity during the recording. Each variable was analyzed for three periods as follows: daytime period from 6 AM to 10 PM, nighttime period from 10 PM to $6 \mathrm{AM}$, and entire 24-hour period. In this investigation we studied the HRV in the time and the frequency domains and the arrhythmic changes after ETS.

The frequency domain analysis was based on a nonparametric method, the fast Fourier transformation, that transformed the individual R-R intervals stored in the computer into bands with different spectral frequencies: the ultralow-frequency band, the very low-frequency band, the 


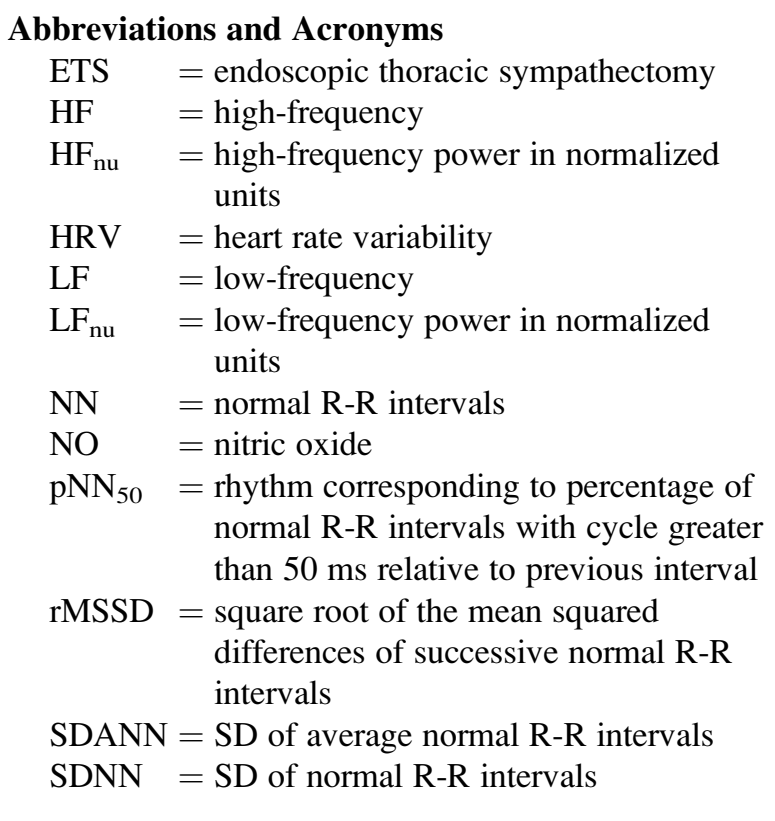

low-frequency band (LF) and the high frequency band (HF). In this study, we retained for analysis the heart rate (expressed in beats/min); R-R mean interval; HF power, LF power, and total power (TP, expressed in $\mathrm{ms}^{2}$ ) and the LF/HF power ratio. LF and HF powers were also expressed as normalized values, $\mathrm{LF}_{\mathrm{nu}}$ and $\mathrm{HF}_{\mathrm{nu}} \cdot{ }^{7}$ The normalization of $\mathrm{LF}$ and HF powers was performed by subtracting the very low-frequency component from the TP value. It tended to reduce the effects of noise caused by artifacts and to minimize the effects of unrelated changes in TP on the LF and HF components.

The TP of R-R interval variability is the total variance of HRV. The HF component is defined as a marker of vagal modulation. The LF component is modulated by both the sympathetic and parasympathetic nervous systems. Some authors interpret LF power, particularly when expressed in normalized units $\left(\right.$ as $L_{\mathrm{nu}}$ ), as a measure of sympathetic modulation, whereas others interpret it as a combination of sympathetic and parasympathetic activities. In practical terms, though, an increase in the LF component has generally been considered to be a consequence of sympathetic activity. The LF/ HF ratio reflects the global sympathovagal balance and can be used as a measure of this balance. ${ }^{13,14}$

Time domain analysis measures the changes in heart rate with time, or the intervals between successive normal cardiac cycles. ${ }^{15,16}$ From a continuous electrocardiographic (24-hour Holter) recording, each QRS complex is detected and the normal R-R intervals (NNs) from sinus depolarizations, or the instantaneous heart rate, are then determined. Time domain analysis included the NNs, the NN mean, the SD of the NNs (SDNN), the SD of the average NNs (SDANN), the square root of the mean squared differences of successive NNs (rMSSD), and the $\mathrm{pNN}_{50}$ rhythm that corresponds to the percentage of NN intervals with a cycle greater than 50 $\mathrm{ms}$ relative to the previous interval. All time domain parameters are expressed in milliseconds, except the $\mathrm{pNN}_{50}$, which is expressed as a percentage.

SDNN is a global index of HRV and reflects all the long-term components and circadian rhythms responsible for variability in the recording period. SDANN is an index of the variability of the average of 5-minute intervals in 24 hours, providing long-term information. It acts as a sensitive index of LF component and is considered a global index of HRV. The rMSSD and $\mathrm{pNN}_{50}$ values, the most common parameters of interval differ- ences, reflect alterations in autonomic tone that are predominantly vagally mediated. ${ }^{7,12}$

The arrhythmic changes recorded during the 24-hour Holter monitoring were analyzed.

\section{Statistical Analysis}

Data are expressed as mean $\pm \mathrm{SD}$ and were compared with the paired $t$ test. All tests were 2-tailed.

\section{RESULTS}

The study population consisted of 28 female and 10 male patients with an average age of 27.5 years (range 15-42 years). No complications were recorded in any patient during or after surgery, and symptoms of palmar and axillary hyperhidrosis disappeared completely after the operation in all cases.

In the frequency domain (Table 1), we observed statistically significant increases in R-R mean after ETS; in HF power (Figure 1) during daytime, nighttime, and 24-hour periods; and in $\mathrm{TP}$ and $\mathrm{HF}_{\mathrm{nu}}$ during daytime and 24-hour periods. We also observed significant decreases in heart rate, $\mathrm{LF}_{\mathrm{nu}}$ (Figure 2), and LF/HF (Figure 3) in all periods. We did not find statistically significant differences in LF power during daytime, nighttime, and 24-hour periods.

In the time domain (Table 2), we found statistically significant differences in all parameters analyzed. We observed statistically significant decreases in NNs during daytime, nighttime, and 24-hour periods and also saw statistically significant increases in all periods of the other time domain parameters: NN mean, SDNN (Figure 4), SDANN, rMSSD (Figure 5), and $\mathrm{pNN}_{50}$.

There were no significant differences concerning bradyarrhythmias or supraventricular or ventricular ectopic beats before and after surgery.

\section{DISCUSSION}

All the results found after ETS were within the reference range. This means that after the operation, the cardiac electrical function of the patients remained essentially unchanged.

In the frequency domain parameters, we found a statistically significant increase in R-R mean and a decrease in heart rate, reflecting a negative chronotropic effect after ETS. We also saw statistically significant increases in TP, a global cardiac autonomous activity parameter, and in HF power and $\mathrm{HF}_{\mathrm{nu}}$, which are vagal activity parameters. There were statistically significant decreases in $L_{\mathrm{nu}}$, a sympathetic activity parameter, and in LF/HF ratio, which indicates both a decrease in sympathetic activity and an increase in vagal activity.

In the analysis of time domain parameters, we saw statistically significant increases in SDNN and SDANN, which evaluate the global cardiac autonomous activity, and in $\mathrm{pNN}_{50}$ and $\mathrm{rMSSD}$, which are parameters of vagal activity. 
TABLE 1. Frequency domain results

\begin{tabular}{|c|c|c|c|c|c|}
\hline & \multirow[b]{2}{*}{ Baseline (mean \pm SD) } & \multirow[b]{2}{*}{6 mo $($ mean \pm SD $)$} & \multicolumn{2}{|r|}{ Difference } & \multirow[b]{2}{*}{$P$ value } \\
\hline & & & Mean & 95\% Confidence interval & \\
\hline \multicolumn{6}{|c|}{ R-R mean (ms) } \\
\hline $24 \mathrm{~h}$ & $828.9 \pm 130.8$ & $913.3 \pm 129.8$ & 84.4 & $55.3-113.6$ & $<.001$ \\
\hline Daytime & $800.4 \pm 130.9$ & $890.2 \pm 133.4$ & 89.8 & $62.6-117.0$ & $<.001$ \\
\hline Nighttime & $885.1 \pm 155.3$ & $971.7 \pm 146.1$ & 86.6 & $39.6-133.6$ & .001 \\
\hline \multicolumn{6}{|c|}{ Heart rate (beats/min) } \\
\hline $24 \mathrm{~h}$ & $75.3 \pm 10.6$ & $68.0 \pm 9.4$ & -7.4 & -9.7 to -5.0 & $<.001$ \\
\hline Daytime & $77.8 \pm 10.8$ & $69.6 \pm 10.0$ & -8.2 & -10.4 to -6.0 & $<.001$ \\
\hline Nighttime & $70.3 \pm 13.0$ & $63.6 \pm 9.6$ & -6.8 & -10.5 to -3.1 & .001 \\
\hline \multicolumn{6}{|c|}{ Total power $\left(\mathrm{ms}^{2}\right)$} \\
\hline $24 \mathrm{~h}$ & $6545.5 \pm 8397.6$ & $7934.1 \pm 8257.1$ & 1388.6 & $82.3-2694.9$ & .038 \\
\hline Daytime & $6781.5 \pm 9962.4$ & $8286.0 \pm 10959.1$ & 1504.6 & $658.5-2350.6$ & .001 \\
\hline Nighttime & $6404.7 \pm 7616.4$ & $7851.4 \pm 7857.7$ & 1446.7 & $535.1-4428.5$ & .329 \\
\hline \multicolumn{6}{|c|}{ Low-frequency power $\left(\mathrm{ms}^{2}\right)$} \\
\hline $24 \mathrm{~h}$ & $1833.4 \pm 1468.1$ & $1633.0 \pm 1420.7$ & -200.4 & $-531.3-130.4$ & .225 \\
\hline Daytime & $1836.2 \pm 1687.5$ & $1737.7 \pm 1472.1$ & -98.4 & $-445.5-248.6$ & .565 \\
\hline Nighttime & $1783.3 \pm 1598.8$ & $1522.7 \pm 1497.3$ & -260.6 & $-813.4-292.1$ & .342 \\
\hline \multicolumn{6}{|c|}{$\begin{array}{l}\text { Low-frequency power } \\
\text { in normalized units }\end{array}$} \\
\hline $24 \mathrm{~h}$ & $63.4 \pm 13.0$ & $53.6 \pm 15.7$ & -9.8 & -13.4 to -6.2 & $<.001$ \\
\hline Daytime & $66.3 \pm 13.2$ & $57.9 \pm 16.3$ & -8.3 & -12.3 to -4.4 & $<.001$ \\
\hline Nighttime & $58.3 \pm 14.8$ & $46.8 \pm 17.8$ & -11.4 & -17.1 to -5.8 & $<.001$ \\
\hline \multicolumn{6}{|c|}{ High-frequency power $\left(\mathrm{ms}^{2}\right)$} \\
\hline $24 \mathrm{~h}$ & $1184.2 \pm 1210.8$ & $1717.7 \pm 1805.2$ & 533.5 & $196.7-870.2$ & .003 \\
\hline Daytime & $1060.3 \pm 1252.7$ & $1581.2 \pm 1636.6$ & 520.9 & $251.8-790.0$ & .001 \\
\hline Nighttime & $1308.3 \pm 1360.0$ & $1958.2 \pm 2303.9$ & 649.9 & $21.2-1278.7$ & .043 \\
\hline \multicolumn{6}{|c|}{$\begin{array}{l}\text { High-frequency power } \\
\text { in normalized units }\end{array}$} \\
\hline $24 \mathrm{~h}$ & $34.2 \pm 11.4$ & $40.8 \pm 13.6$ & 6.6 & $3.2-10.0$ & $<.001$ \\
\hline Daytime & $30.9 \pm 11.5$ & $38.8 \pm 14.3$ & 7.9 & $4.2-11.6$ & $<.001$ \\
\hline Nighttime & $39.6 \pm 13.5$ & $43.4 \pm 14.8$ & 3.8 & $-1.5-9.1$ & .152 \\
\hline \multicolumn{6}{|c|}{ Low-/high-frequency power ratio } \\
\hline $24 \mathrm{~h}$ & $3.3 \pm 1.8$ & $2.3 \pm 1.8$ & -0.9 & -1.3 to -0.5 & $<.001$ \\
\hline Daytime & $3.7 \pm 2.0$ & $2.7 \pm 2.3$ & -1.0 & -1.5 to -0.5 & $<.001$ \\
\hline Nighttime & $2.6 \pm 1.6$ & $1.8 \pm 1.4$ & -0.7 & -1.3 to -0.2 & .008 \\
\hline
\end{tabular}

In summary, in this investigation we found statistically significant differences in both time and frequency domains. The parameters that evaluate the global cardiac autonomous activity (TP, SDNN, SDANN) and the vagal activity (pNN50, rMSSD, HF power, $\mathrm{HF}_{\mathrm{nu}}$ ) had statistically significant increases after ETS. LF $_{\text {nu }}$, which reflects the sympathetic activity, had a statistically significant decrease after ETS. The significant decrease in LF/HF ratio also indicates a relative decrease in sympathetic activity and an increase in vagal activity. These results provide clear and consistent evidence pointing toward increases in vagal and global cardiac autonomous activities after ETS.

Noppen and colleagues, ${ }^{8}$ Tygesen and associates, ${ }^{9}$ Tedoriya and colleagues, ${ }^{10}$ Wettervik and coworkers, ${ }^{11}$ Abraham and associates, ${ }^{17}$ and Drott and colleagues ${ }^{18}$ had previously studied the cardiac effects of ETS in patients with primary hyperhidrosis, and they reported an increase of R-R mean and a decrease in heart rate, confirming the negative chronotropic effect of ETS. Abraham et and colleagues, ${ }^{17}$ who also studied HRV with 24-hour Holter recordings, demonstrated statistically significant decreases in heart rate, LF power, and $\mathrm{LF} / \mathrm{HF}$ ratio but did no find any differences in all other parameters studied. They concluded that a decrease of sympathetic activity was observed, but without any difference in vagal activity. Tedoriya and colleagues ${ }^{10}$ found a significantly decrease only in LF/HF ratio in the head-up tilt position after surgery and concluded that the influences of ETS on the cardiac autonomic nerve system were of a lesser degree at rest, but the response to sympathetic stimulation was suppressed after surgery. Wilkund and coworkers ${ }^{19}$ verified that the patients with primary hyperhidrosis had a tendency toward higher power in the LF and HF components than seen in control subjects in the upright position. After sympathectomy, LF power was reduced, but HF power was 


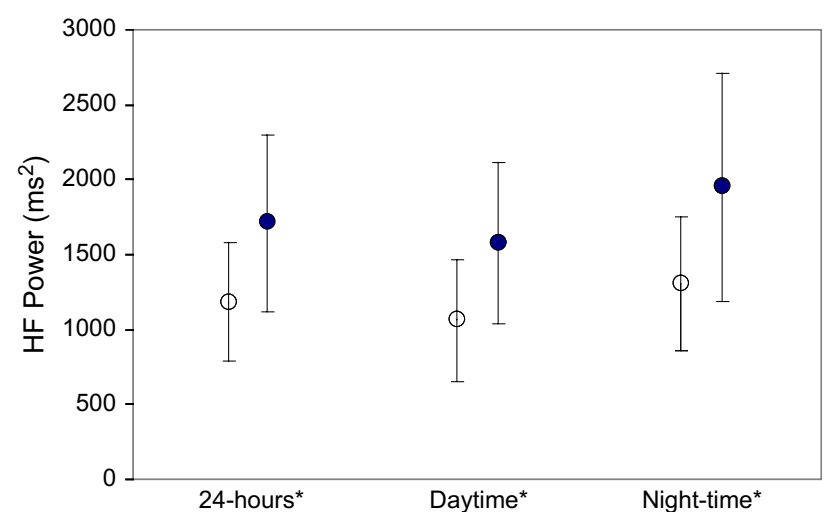

FIGURE 1. High-frequency power $(H F)$ before (open circles) and after (closed circles) sympathectomy. Mean and $95 \%$ confidence interval; asterisk indicates $P<.05$.

unchanged. At follow-up, LF power remained at a lower level, but now HF power was reduced. They concluded that patients with palmar hyperhidrosis have sympathetic hyperactivity but with a compensatory high parasympathetic activity. Sympathectomy results in an initial sympathovagal imbalance with a parasympathetic predominance, which is restored on a long-term basis. The results of these investigations revealed a decrease in sympathetic activity but failed to show an increase in vagal activity. Why these investigators were not able to show the decrease in vagal activity decrease in our study can be explained, in our opinion, by our selection of 24-hour Holter recordings in this investigation and the larger number of cases studied (38 patients) than in the other studies (between 10 and 13 patients).

In summary, the articles discussed here consistently showed a negative chronotropic effect, suggesting a decrease in sympathetic activity, but failed to show an increase in vagal activity. ${ }^{8-11,17-19}$ In contrast, our investigation demonstrated that ETS in patients with primary hyperhidrosis causes increases in vagal and cardiac autonomic activities and a decrease in sympathetic activity. As far as we know, this is the first time that these results have been presented in such a clear way.

These results confirm that the second and third sympathetic thoracic ganglia excised in ETS do influence the autonomous cardiac activity. Because of the anatomic variability of the cardiac sympathetic efferent innervations of second and third thoracic ganglia that usually are rare, however, it is difficult to explain these results as a consequence of cardiac adrenergic efferent section. ${ }^{20-22}$ We therefore can consider the hypothesis that the effects we have found are a consequence of cardiac adrenergic afferent section. In fact, Malliani, ${ }^{23}$ Ruscone and coworkers, ${ }^{24}$ and Bishop and associates ${ }^{25}$ demonstrated in experimental works the importance of cardiac sympathetic afferents in the autonomic modulation of the heart. Foreman, ${ }^{26}$ in studies in rabbits, also demonstrated that the second and third tho-

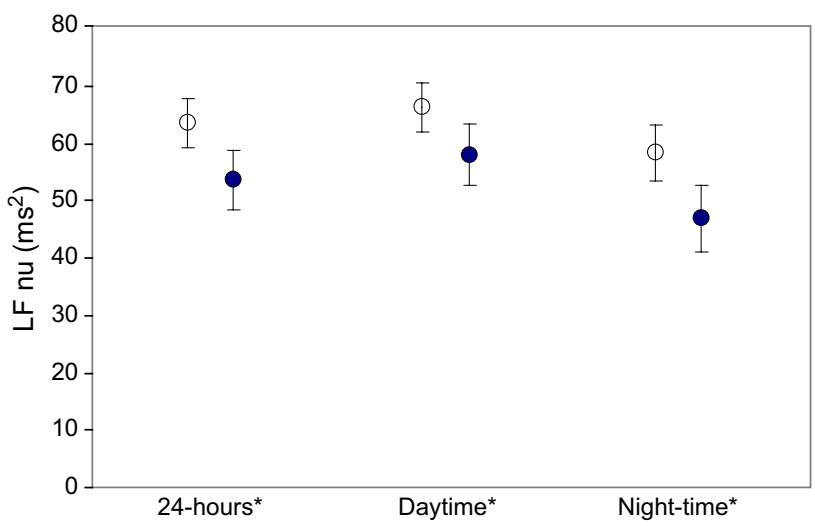

FIGURE 2. Low-frequency power in normalized units $\left(L F_{n u}\right)$ before (open circles) and after (closed circles) sympathectomy. Mean and 95\% confidence interval; asterisk indicates $P<.05$.

racic ganglia received an important number of sympathetic afferents. We do not know if the human second and third thoracic ganglia also have a superior number of sympathetic afferents, but we can hypothesize that the observed cardiac effects in HRV analysis are probably not the result of sympathetic efferent nerve section but rather of the cardiac afferent nerves of the second and third thoracic ganglia.

Another hypothesis that we have formulated to explain our results is the relationship between ETS and increased nitric oxide (NO) activity. ${ }^{27,28}$ The sympatholytic activity of $\mathrm{NO}$, with an adrenergic decrease and a vagal activity increase, has been demonstrated. ${ }^{29,30}$ Chowdhary and coworkers $^{29}$ studied the effects of NO in healthy people and confirmed that this substance increases cardiac vagal activity. Although the study of Chowdhary and coworkers ${ }^{29}$ was performed in healthy people, if these effects can be generalized to patients with primary hyperhidrosis, an increase in NO activity after ETS could, in our opinion, explain the higher vagal activity. These hypothesis seems consistent,

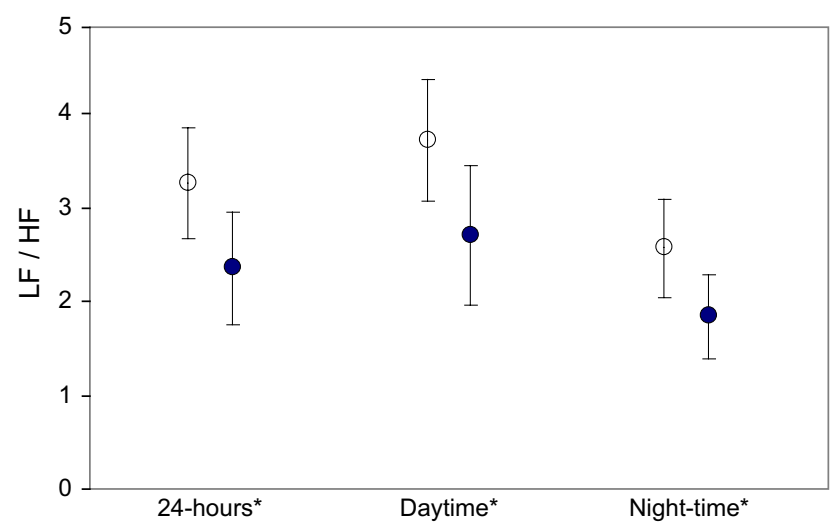

FIGURE 3. Low-/high-frequency $(L F / H F)$ ratio before (open circles) and after (closed circles) sympathectomy. Mean and 95\% confidence interval; asterisk indicates $P<.05$. 
TABLE 2. Time domain results

\begin{tabular}{|c|c|c|c|c|c|}
\hline & \multirow[b]{2}{*}{ Baseline (mean \pm SD) } & \multirow[b]{2}{*}{6 months $($ mean \pm SD) } & \multicolumn{2}{|r|}{ Difference } & \multirow[b]{2}{*}{$P$ value } \\
\hline & & & Mean & $\mathbf{9 5} \%$ Confidence interval & \\
\hline \multicolumn{6}{|c|}{ Normal R-R intervals } \\
\hline $24 \mathrm{~h}$ & $4243 \pm 565.1$ & $3725.1 \pm 608.6$ & -518.1 & -731.1 to -305.0 & $<.0001$ \\
\hline Daytime & $4391.6 \pm 605.5$ & $3847.3 \pm 682.7$ & -544.3 & -726.9 to -361.6 & $<.0001$ \\
\hline Nighttime & $3953.8 \pm 570.2$ & $3624.6 \pm 504.6$ & -329.2 & -555.8 to -102.6 & .0060 \\
\hline \multicolumn{6}{|c|}{ Mean of normal R-R intervals (ms) } \\
\hline $24 \mathrm{~h}$ & $814.6 \pm 111.7$ & $892.0 \pm 115.4$ & 77.4 & $48.5-106.2$ & $<.0001$ \\
\hline Daytime & $779.0 \pm 97.5$ & $843.4 \pm 121.4$ & 64.4 & $38.6-90.2$ & $<.0001$ \\
\hline Nighttime & $879.5 \pm 153.9$ & $968.0 \pm 131.3$ & 88.4 & $43.3-133.6$ & .0004 \\
\hline \multicolumn{6}{|c|}{ SD of normal R-R intervals (ms) } \\
\hline $24 \mathrm{~h}$ & $91.8 \pm 26.6$ & $100.7 \pm 28.6$ & 8.9 & $4.1-13.9$ & .0010 \\
\hline Daytime & $96.3 \pm 27.9$ & $104.3 \pm 30.1$ & 8.1 & $3.7-12.2$ & .0007 \\
\hline Nighttime & $85.5 \pm 27.4$ & $96.0 \pm 29.3$ & 10.5 & $2.8-18.2$ & .0093 \\
\hline \multicolumn{6}{|c|}{ SD index of normal R-R intervals (ms) } \\
\hline $24 \mathrm{~h}$ & $72.6 \pm 23.2$ & $79.8 \pm 24.8$ & 7.3 & $3.1-11.4$ & .0014 \\
\hline Daytime & $75.4 \pm 24.8$ & $81.9 \pm 26.7$ & 6.5 & $2.6-10.4$ & .0021 \\
\hline Nighttime & $69.7 \pm 22.6$ & $77.2 \pm 24.5$ & 8.3 & $2.2-14.3$ & .0090 \\
\hline \multicolumn{6}{|c|}{$\begin{array}{l}\text { Mean squared differences of successive } \\
\text { normal } \mathrm{R}-\mathrm{R} \text { intervals (ms) }\end{array}$} \\
\hline $24 \mathrm{~h}$ & $49.6 \pm 21.4$ & $60.0 \pm 26.8$ & 10.5 & $5.4-15.6$ & .0002 \\
\hline Daytime & $49.0 \pm 21.4$ & $58.6 \pm 26.3$ & 9.6 & $4.9-14.3$ & .0003 \\
\hline Nighttime & $51.5 \pm 23,4$ & $63.5 \pm 30.9$ & 12.0 & $4.6-19.5$ & .0026 \\
\hline \multicolumn{6}{|l|}{$\mathrm{pNN}_{50} *(\%)$} \\
\hline $24 \mathrm{~h}$ & $18.2 \pm 13.2$ & $25.4 \pm 15.3$ & 7.2 & $4.4-10.0$ & $<.0001$ \\
\hline Daytime & $17.1 \pm 12.6$ & $22.8 \pm 15.1$ & 5.7 & $3.3-8.2$ & $<.0001$ \\
\hline Nighttime & $20.6 \pm 15.9$ & $30.0 \pm 18.9$ & 9.4 & $4.6-14.3$ & .0005 \\
\hline \multicolumn{6}{|c|}{ SD of average normal R-R intervals (ms) } \\
\hline $24 \mathrm{~h}$ & $47.2 \pm 12.1$ & $52.8 \pm 14.2$ & 5.7 & $2.5-8.9$ & .0012 \\
\hline Daytime & $50.6 \pm 12.9$ & $56.3 \pm 15.0$ & 5.7 & $2.1-9.4$ & .0030 \\
\hline Nighttime & $40.9 \pm 13.84$ & $46.3 \pm 15.3$ & 5.4 & $0.8-10.0$ & .0227 \\
\hline
\end{tabular}

*Rhythm corresponding to percentage of normal R-R intervals with cycle greater than $50 \mathrm{~ms}$ relative to previous interval.

and we therefore believe in the importance of pursuing the investigation regarding NO activity in cardiac autonomic control before and after ETS in patients with primary hyperhidrosis.

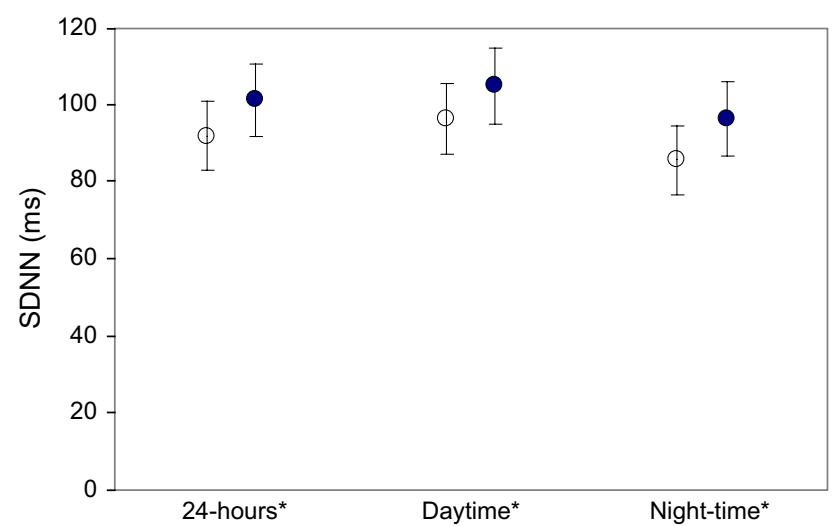

FIGURE 4. SD of normal R-R intervals ( $S D N N$ ) before (open circles) and after (closed circles) sympathectomy. Mean and $95 \%$ confidence interval; asterisk indicates $P<.05$.
It is important to underline that our study population was composed of patients who already had an autonomic dysfunction disorder. We do not know whether primary hyperhidrosis is a systemic or a local disease. As we stated before,

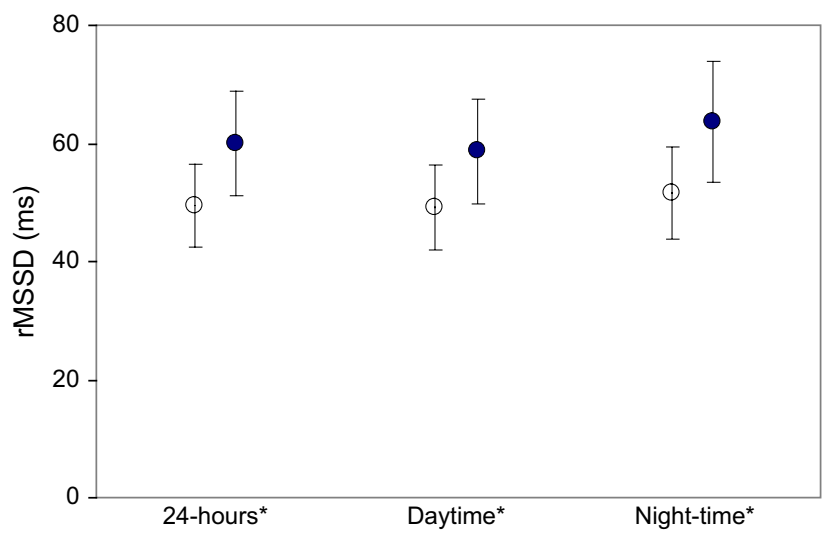

FIGURE 5. Square root of mean squared differences of successive normal R-R intervals ( $r M S S D$ ) before (open circles) and after (closed circles) sympathectomy. Mean and $95 \%$ confidence interval; asterisk indicates $P<.05$. 
however, in our opinion, sweating in patients with primary hyperhidrosis apparently has no homeostatic function. This means that our sample has specific clinical characteristics, which makes us believe that the observed cardiac effects in patients with primary hyperhidrosis undergoing ETS would probably not be observed in healthy individuals.

\section{CONCLUSIONS}

In this prospective study, we demonstrated with statistically significant results in both time and frequency domain analyses a decrease in sympathetic activity, an increase in vagal activity, and increase in R-R variability 6 months after ETS in patients with primary hyperhidrosis.

\section{References}

1. Krasna MJ. Thoracoscopic sympathectomy: a standardized approach to therapy for hyperhidrosis. Ann Thorac Surg. 2008;85:S764-7.

2. Cruz J, Caldeira J, Cravino J. Simpaticectomia Torácica Video-assistida no tratamento da hiperhidrose palmar e axilar. Rev Port CCT e Vasc. 2002;9:149-52.

3. Lin CC, Mo LR, Lee LS. Thoracoscopic T2 sympathetic block by clipping. A better and reversible operation for treatment of hyperhidrosis palmaris: experience with 326 cases. Eur J Surg Suppl. 1998;S580:13.

4. Singh B, Shaik AS, Moodley J, Ramdial P, Rajaruthnam P. Limited thoracoscopic ganglionectomy for primary hyperhidrosis. S Afr J Surg. 2002;40:50-3.

5. Han PP, Gottfried ON, Kenny KJ, Dickman CA. Biportal thoracoscopic sympathectomy: surgical techniques and clinical results for the treatment of hyperhidrosis. Neurosurgery. 2002;50:306-11.

6. Lin TS, Huang LC, Wang NP, Chang CC. Endoscopic thoracic sympathetic block by clipping for palmar and axillary hyperhidrosis in children and adolescents. Pediatr Surg Int. 2001;17:535-7.

7. Task Force of the European Society of Cardiology and the North American Society of Pacing and Electrophysiology. Heart rate variability: standards of measurement, physiological interpretation, and clinical use. Circulation. 1996;93:1043-65.

8. Noppen M, Dendale P, Hagers Y, Herregodts P, Vincken W, D'Haens J. Changes in cardiocirculatory autonomic function after thoracoscopic upper dorsal sympathicolysis for essential hyperhidrosis. J Auton Nerv Syst. 1996;60:115-20.

9. Tygesen H, Claes G, Drott C, Emanuelsson H, Lomsky M, Lurje L, et al. Effects of endoscopic transthoracic sympathicotomy on heart rate variability in severe angina pectoris. Am J Cardiol. 1997;79:1447-52.

10. Tedoriya T, Sakagami S, Ueyama T, Thompson L, Hetzer R. Influences of bilateral endoscopic transthoracic sympathicotomy on cardiac autonomic nervous activity. Eur J Cardiothorac Surg. 1999;15:194-8.

11. Wettervik C, Claes G, Drott C. Endoscopic transthoracic sympathicotomy for severe angina. Lancet. 1995;345:97-8.
12. Sztajzel J. Heart rate variability: a noninvasive electrocardiographic method to measure the autonomic nervous system. Swiss Med Wkly. 2004;134:514-22.

13. Malliani A, Lombardi F, Pagani M. Power spectrum analysis of heart rate variability: a tool to explore neural regulatory mechanisms. Br Heart J. 1994; 71:1-2.

14. Eckberg DL. Sympathovagal balance. Circulation. 1997;96:3224-32.

15. Malik M. Measurement of heart rate variability. In: Malik M, Camm J, eds. Heart rate variability. Armonk (NY): Futura; 1995:33-132.

16. Kleiger RE, Stein PK, Bosner MS, Rottman JN. Time domain measurements of heart rate variability. Cardiol Clin. 1992;10:487-98.

17. Abraham P, Berthelot J, Victor J, Saumet J, Picqet J, Enon B. Holter changes resulting from right-sided and bilateral infrastellate upper thoracic sympathectomy. Ann Thorac Surg. 2002;74:2076-81.

18. Drott C, Claes G, Gothberg G, Paszkowski P. Cardiac effects of endoscopic electrocautery of the upper thoracic sympathetic chain. Eur J Surg Suppl. 1994;572: $65-70$.

19. Wiklund U, Koskinen LO, Niklasson U, Bjerle P, Elfversson J. Endoscopic transthoracic sympathicotomy affects the autonomic modulation of heart rate in patients with palmar hyperhidrosis. Acta Neurochir (Wien). 2000; 142:691-6.

20. Jeffrey PE, Terence HW. Sympathetic nerve pathways to the human heart and their variations. Am J Anat. 1969;124:149-62.

21. Janes R, Christopher B, David AH, David EJ, David AM, Andrew A. Anatomy of human extrinsic cardiac nerves and ganglia. Am J Cardiol. 1986;57: 299-309.

22. Ellison JP, Williams TH. Sympathetic nerve pathways to the human heart, and their variations. Am J Anat. 1969;124:149-62.

23. Malliani A. General concepts and hypotheses in the study of cardiovascular neural regulation. In: Malliani A, ed. Principles of cardiovascular neural regulation in health and disease. Norwell (MA): Kluwer Academic; 2000:1-29.

24. Ruscone T, Lombardi F, Malfatto G, Malliani A. Attenuation of baroreceptive mechanisms by cardiovascular sympathetic afferent fibers. Am J Physiol. 1987; 253:787-91.

25. Bishop VS, Lombardi F, Malliani A, Pagani M, Recordati G. Reflex sympathetic tachycardia during intravenous infusion in chronic spinal cats. Am J Physiol. 1976;230:25-9.

26. Foreman R. Spinal cord neuronal regulation of the cardiovascular system. In: Armour J, Ardell J, eds. Neurocardiology. New York: Oxford University Press (USA); 1994:245-76.

27. Lepori M, Sartori C, Duplain D, Nicod P, Scherrer U. Sympathectomy potentiates the vasoconstrictor response to nitric oxide synthase inhibition in humans. Cardiovasc Res. 1999;43:739-43.

28. Charkoudian N, Eisenach JH, Atkinson JL, Fealey RG, Joyner MJ. Effects of chronic sympathectomy on locally mediated cutaneous vasodilatation in humans. J Appl Physiol. 2001;92:685-90.

29. Chowdhary S, Vaile J, Fletcher J, Ross H, Coote J, Townend N. Nitric oxide and cardiac autonomic control in humans. Hypertension. 2000;36:264-9.

30. Chowdhary S, Townend N. Role of nitric oxide in the regulation of cardiovascular autonomic control. Clin Sci'. 1999;97:5-17. 